\title{
Screening of methicillin resistant Staphylococcus aureus from dogs and cats in Hyderabad Pakistan
}

Imtiaz Ali Ujjan ${ }^{1 *}$, Jam Kashif Zaman ${ }^{1}$, Nazeer Hussain Kalhoro², Amjad Hussain Mirani ${ }^{1}$, Abdul Latif Bhutto ${ }^{1}$, Ahmed Nawaz Khosa ${ }^{3}$, Banzir Sahito ${ }^{1}$, Chandni Wajid ${ }^{3}$, Asma Babar ${ }^{3}$, Zain ul Aabdin ${ }^{1}$, Muhammad Azhar Memon ${ }^{1}$ and Waseem Ali Vistro ${ }^{1}$

1. Faculty of Animal Husbandry and Veterinary Science, Sindh Agriculture University Tandojam-Pakistan

2. Sindh institute of Animal Health Korangi Karachi-Pakistan

3. Animal breeding and genetics, Faculty of Veterinary \& Animal Sciences, LUAWMS-Pakistan

*Corresponding author's email: imtiazujjan61@gmail.com

Citation

Imtiaz Ali Ujjan, Jam Kashif Zaman, Nazeer Hussain Kalhoro, Amjad Hussain Mirani, Abdul Latif Bhutto, Ahmed Nawaz Khosa, Banzir Sahito, Chandni Wajid, Asma Babar, Zain ul Aabdin, Muhammad Azhar Memon and Waseem Ali Vistro. Screening of methicillin resistant Staphylococcus aureus from dogs and cats in Hyderabad Pakistan. Pure and Applied Biology. Vol. 10, Issue 4, pp969-977.

http://dx.doi.org/10.19045/bspab.2021.100101

\begin{tabular}{llll}
\hline \hline Received: 19/10/2020 & Revised: 18/12/2020 & Accepted: 28/12/2020 & Online First: 02/01/2021 \\
\hline
\end{tabular}

\section{Abstract}

Methicillin-resistant Staphylococcus aureus (MRSA) is a "superberg", an important cause of human nosocomial and as a universal community-acquired infection cause resistant to $\beta$-lactam antibiotics. Till to date no detailed and authentic report on MRSA in nasal swabs of diseased dogs and cats reported. This study was planned to check the presence of MRSA in nasal swabs of dogs and cats. Total 100 samples were collected, and 37 samples were positive with $S$. aureus in both diseased dogs and cats which were confirmed by their colony characteristic, morphology, gram stain reaction and biochemical properties. These isolates were subjected to minimum inhibitory concentration (MIC) through Micro broth dilution method by using methicillin in 96 well plates. Among them, 8/37 (21.62\%) were found methicillin resistant. In diseased dog, 5/21 (23.80\%) and cat 3/16 (18.75\%) isolated were found moderately resistant to methicillin as they grew at $32 \mu \mathrm{g} / \mu \mathrm{l}$ concentration of methicillin. mec- $A$ gene in methicillin resistant samples were detected through polymerase chain reaction (PCR). This resistance was due to phenotypically and moderate level of the resistance against methicillin with absence of $m e c-A$ gene shows that the examined pets were not the reservoir of $m e c-A$ gene. However, more studies are recommended to further confirm that, pets are reservoir of mec-A gene or not or this may be due to involvement of sharing mechanism of resistance to penicillin group. So far, this is first study on MRSA in diseased dog and cats, which revealed that, there is no MRSA in this area of Pakistan.

Keywords: Cat; Dog; Methicillin resistant; Screening; Staphylococcus aureus

\section{Introduction}

Antibiotics are generally used to treat for variety of bacterial infection in veterinary and human practice and these antibiotics produced their action by either stopping the bacterial growth or directly killing microbes. The broad spectrum antibiotics have killed all type of bacteria including gram positive and gram negative whereas narrow spectrum antibiotics are effected on 
either gram positive or gram negative bacteria [1].

Antibiotic agent of $\beta$-lactam antibiotics contains a $\beta$-lactam ring in their molecular structures. The $\beta$-lactam resistant penicillin consist of methicillin, oxacillin and cloxacillin were used in first line of treatment as penicillin-resistant $S$. aureus and the $\beta$-lactam antibiotics are frequently used for Staphylococcal infections as a result antibiotic acquired resistance has developed [2]. The different derivates of Penicillin including Methicillin has been used for the infection occurred through $S$. aureus [3]. The most penicillin derivatives are resistant to $90 \%$ of $S$. aureus strains However, many species of $S$. aureus have developed resistance recognized as MRSA [4]. The first antibiotic was Methicillin which introduced in human medicine used as methicillin resistant Staphylococcal infection in 1950s and more than $80 \%$ of $S$. aureus have produced Penicillinase enzyme, caused resistant to $\beta$-lactam antibiotics which commonly used to treat Staphylococcal infections in dogs and cats [5].

Antimicrobial resistance is a major threat in veterinary and human medicine and the most important antimicrobial resistance has developed due to use and misuse of antibiotics in veterinary field and human medicine [6]. MRSA known as an important cause of human nosocomial and as a universal community-acquired infection cause resistant to $\beta$--lactam antibiotics was facilitated by the mec-A gene, present in bacterial cell wall which encodes to penicillin-binding protein $(P B P 2 a)$ for reducing the affinity of $\beta$-lactam antibiotics [7]. MRSA kills more people than the acquired immunodeficiency syndrome (AIDS) because of it known as the "superbug" [8]. The mobile genetic element (mec-A) gene is fragment of a $21 \mathrm{~kb}$ to $60-\mathrm{kb}$ Staphylococcal chromosome cassette mec (SCCmec). The mec-A gene is characterized by the combination of $c c r$ and mec which encode resistance to $\beta$-lactam antibiotics [9]. Pets contain emerging and prevalent pathogenic species of Staphylococcus aureus [10]. Dogs and cats can be a potential reservoir of MRSA infection for human and contact with large part of human population so there is the potential for transfer of MRSA or mec-A gene among human and cats and dogs. The risk factor for MRSA infections were intravenous catheter and drugs used in veterinary medicine in cats and dogs and MRSA infection is becoming a public health concern because dogs and cats are in close connection with their owners, risk them for transmission of highly pathogenic strain of MRSA [11].

Considering this screening present study was designed to check the presence of highly pathogenic and zoonotic organism in pets (cats and dogs) from in order to analyses the possible pathogenic thread of spread of MRSA from cats and dogs to human. Results of this study will provide information to the veterinary field as well as human clinicians about the prevalence of Methicillin resistant strains of $S$. aureus in pets.

\section{Materials and Methods Study area}

All samples were collected from nasal swabs of diseased dogs and cats from the Hyderabad and its vicinity. The clinically ill dogs and cats were selected in this study and samples were collected from different Pets clinics of Hyderabad and its vicinity.

\section{Collection of sample}

A total of 100 samples were collected, 50 samples were collected from diseased dogs and 50 samples were collected from the diseased cats and brought to the veterinary clinics for collection of nasal swabs. Samples were collected in Tran swab tube containing Amies medium.

All samples were brought to the bacteriology section of Central Veterinary Diagnostic Laboratory (CVDL) Tandojam in a portable cooler containing an ice pack and then swabs were refrigerated at $4{ }^{\circ} \mathrm{C}$ until being processed within $48 \mathrm{hr}$ of collection for isolation and identification of $S$. aureus by chain of laboratory technique 
including colony characteristics, gram staining, and growth on blood agar. The isolates of $S$. aureus were cultured on Tryptic Soy Broth (TSB) at $37{ }^{\circ} \mathrm{C}$ for further experimental use.

\section{Antimicrobial susceptibility test}

The $S$. aureus isolates were determined through Minimum inhibitory concentration test by using (Micro Broth 2-fold dilution method) on Muller Hinton (MH) agar (Oxide, UK) and 1:1000 dilution was prepared for MIC test for that $6 \mu \mathrm{l}$ of bacterial culture of $S$. aureus in Nutrient broth were added into $6 \mathrm{ml}$ of Muller Hinton broth.

96 well plates of micro titer tray were used for MIC test and a concentration $1280 \mu 1 / \mathrm{ml}$ of Methicillin (Sigma, USA) was used for minimum inhibitory concentration against S. aureus.

$S$. aureus isolates in nutrient broth culture were added in each well of micro titer tray. In first well $180 \mu 1$ of culture were added and in remaining all wells $100 \mu 1$ of bacterial culture were added than $20 \mu$ of Methicillin (Sigma, USA) were added in first well and mixed by push up of Eppendorf tube then $100 \mu 1$ of culture from first well were introduced into next well and repeat till last well. The final sub cultures of bacterial isolates were discarding. Then MIC plates were placed in incubator at $37{ }^{\circ} \mathrm{C}$ for 24 hours. Results of MIC test were obtained by performing MIC test three times.

\section{Molecular examination of resistant $S$.} aureus Isolates

Molecular examination of resistant $S$. aureus isolates was done in molecular laboratory of Sindh Poultry Vaccine Centre (SPVC) Karachi.

\section{DNA extraction}

The DNA was extracted by using commercial kit (Geneaid GEE 300, GEE $\mathrm{O} 3 \mathrm{~K})$ as per manufacturers' instruction. Following Specific primers were used for detection of mec- $A$ gene from Staphylococcus aureus.

F-ATGAAATGACTGAACGTCCGATT A,

R-CAAATTCCA CATTGTTTCGGTCT
AA.

The PCR reaction mixture $50 \mu 1$, which include following reagents.

1. PCR master mixture: $25 \mu 1$

2. RNase free water: $17 \mu \mathrm{l}$

3. Forward primer: $\quad 2 \mu \mathrm{l}$

4. Reverse primer: $\quad 2 \mu 1$

5. DNA/sample: $\quad 4 \mu 1$

PCR protocol

After DNA extraction, PCR was performed in Applied Bio system 2720 thermal cycler (Eppendorf). Total of 50 $\mu$ lof PCR reaction mixture was prepared for each supernatant DNA for that $25 \mu 1$ PCR master mixture was added into Eppendorf tube then $17 \mu$ of RNase free water was added into same Eppendorf tube then added $2 \mu 1$ of forward primer followed by $2 \mu \mathrm{l}$ of reverse prime were mixed with $4 \mu \mathrm{l}$ of supernatant DNA Gently, mixed by vortex and then kept tubes in thermal cycler. A thermal cycler was used for amplification of DNA then cycling condition of PCR was set such as initial denaturation at $95{ }^{\circ} \mathrm{C}$ for 05 minutes, followed by 35 cycles of denaturation at 95 ${ }^{\circ} \mathrm{C}$ for 01 minute annealing at $55{ }^{\circ} \mathrm{C}$ for 45 seconds, extension at $72{ }^{\circ} \mathrm{C}$ for 45 seconds and final cycling of amplification was done at $72{ }^{\circ} \mathrm{C}$ for 5 minutes. The amplified product was analyzed through gel electrophoresis processes by using $3 \mu \mathrm{l}$ ethidium bromide and 2\% agarose gel and DNA band was visualized by ultraviolet light.

\section{Results \\ Percentage prevalence of $S$. aureus in diseased dogs and cats}

To isolates the $S$. aureus, one hundred samples were collected from nasal swabs of diseased dogs and cats. All samples were cultured on different media to isolates pure colony of $S$. aureus then pure cultures of organism were confirmed through grams staining. Further pure cultures were confirmed by the biochemical properties. From all samples only 37 were found positive with $S$. aureus colony in both diseased dogs and cats (Table 1). 
Percentage prevalence of $S$. aureus isolated from nasal swabs of diseased dogs and cats.

A total of 50/50 samples were collected from nasal swabs of diseased dogs and cats, only 21 and 16 samples were found positive with $S$. aureus isolates shown in (Table 2).

Colony characteristic of Staphylococcus aureus isolated from diseased Dogs and Cats

The colonies of Staphylococcus aureus produced yellow or white colony and typical characteristic of $\beta$-hemolysis of red blood cell was recorded on blood agar.

Morphological characteristic of $S$. aureus isolated from diseased dogs and cats

S. aureus was confirmed through grams staining. The positive samples of $S$. aureus were characterized as gram positive, spherical in shape, and arranged in pairs like cocci.

Biochemical characteristic of $S$. aureus isolates

The $S$. aureus isolates was recorded positive for coagulase, urease, methyl red and Voges- Proskauer and S. aureus was found negative for indole and oxidase test. $S$. aureus isolates on Triple Sugar Iron agar (TSI) medium were showed A/A properties that meant this $S$. aureus isolates showing the property of acidic slant and acidic butt that indicate that the sugar present in the media was fermented (Table 3).

Minimum inhibitory concentration of $S$. aureus isolates

All 21 and 16 positive isolates of $S$. aureus were selected for MIC test. Only 05 and 03 samples were shown resistance at different concentration of Methicillin in diseased dogs and cat shown in (Table 4).

Table 1. Percentage prevalence of S. aureus isolated from nasal swabs of diseased dogs and cats

\begin{tabular}{|c|c|c|}
\hline Total number of samples & No. of positive samples & Percentage \\
\hline 100 & 37 & $37 \%$ \\
\hline
\end{tabular}

Table 2. Percentage prevalence of $S$. aureus in diseased dogs and cats

\begin{tabular}{|c|c|c|c|}
\hline Animal & Total number of samples & No. of positive samples & Percentage \\
\hline Dog & 50 & 21 & $42 \%$ \\
\hline Cat & 50 & 16 & $32 \%$ \\
\hline
\end{tabular}

Table 3. Biochemical characteristic of $S$. aureus isolated from nasal swabs of diseased dogs and cats

\begin{tabular}{|l|c|c|c|c|c|c|c|c|c|}
\hline S.aureus & Coag & Ure & M.R & V.P & Ind & Oxid & Cit & TSI & Cat \\
\hline & $+v e$ & $+v e$ & $+v e$ & $+v e$ & $-v e$ & $-v e$ & $+v e$ & A/A & $+v e$ \\
\hline
\end{tabular}

Table 4. Number and percentage of Methicillin Resistant $S$. aureus isolates from diseased dogs and cats

\begin{tabular}{|c|c|c|c|}
\hline Animal & Positive & Methicillin resistant & Percentage \\
\hline Dog & 21 & 05 & $23.80 \%$ \\
\hline Cat & 16 & 03 & $18.75 \%$ \\
\hline
\end{tabular}

Minimum inhibitory concentration of $S$. aureus isolates against Methicillin from nasal swabs of diseased dogs

Total of five samples were shown their resistant at the concentration of $16 \mu \mathrm{g} / \mathrm{ml}$ against methicillin in diseased dogs and two samples were shown their resistant at $64 \mu \mathrm{g} / \mathrm{ml}$ concentration of methicillin while other samples no resistant at any concentration of methicillin. The positive sign indicates the bacterial resistant against methicillin and negative sign shows no 
growth of $S$. aureus against methicillin

(Table 5).

Table 5. Minimum inhibitory concentration of $S$. aureus isolates against methicillin from nasal swabs of diseased dogs

\begin{tabular}{|c|c|c|c|c|c|c|c|c|c|}
\hline $\begin{array}{c}\text { Sample } \\
\text { No. }\end{array}$ & $\begin{array}{c}\mathbf{1 2 8} \\
\mu \mathrm{g} / \mathrm{ml}\end{array}$ & $\begin{array}{c}\mathbf{6 4} \\
\mu \mathrm{g} / \mathrm{ml}\end{array}$ & $\begin{array}{c}\mathbf{3 2} \\
\mu \mathrm{g} / \mathrm{ml}\end{array}$ & $\begin{array}{c}\mathbf{1 6} \\
\mu \mathrm{g} / \mathrm{ml}\end{array}$ & $\begin{array}{c}\mathbf{8} \\
\mu \mathrm{g} / \mathrm{ml}\end{array}$ & $\begin{array}{c}\mathbf{4} \\
\mu \mathrm{g} / \mathrm{ml}\end{array}$ & $\begin{array}{c}\mathbf{2} \\
\mu \mathrm{g} / \mathrm{ml}\end{array}$ & $\begin{array}{c}\mathbf{1} \\
\mu \mathrm{g} / \mathrm{ml}\end{array}$ & $\begin{array}{c}\mathbf{0 . 5} \\
\mu \mathrm{g} / \mathrm{ml}\end{array}$ \\
\hline $\mathbf{1}$ & - & + & + & + & + & + & + & + & + \\
\hline $\mathbf{2}$ & - & + & + & + & + & + & + & + & + \\
\hline $\mathbf{3}$ & - & + & + & + & + & + & + & + & + \\
\hline $\mathbf{4}$ & - & - & - & + & + & + & + & + & + \\
\hline $\mathbf{5}$ & - & - & - & + & + & + & + & + & + \\
\hline $\mathbf{6}$ & - & - & - & - & - & - & - & - & - \\
\hline $\mathbf{7}$ & - & - & - & - & - & - & - & - & - \\
\hline $\mathbf{8}$ & - & - & - & - & - & - & - & - & - \\
\hline $\mathbf{9}$ & - & - & - & - & - & - & - & - & - \\
\hline $\mathbf{1 0}$ & - & - & - & - & - & - & - & - & - \\
\hline $\mathbf{1 1}$ & - & - & - & - & - & - & - & - & - \\
\hline $\mathbf{1 2}$ & - & - & - & - & - & - & - & - & - \\
\hline $\mathbf{1 3}$ & - & - & - & - & - & - & - & - & - \\
\hline $\mathbf{1 4}$ & - & - & - & - & - & - & - & - & - \\
\hline $\mathbf{1 5}$ & - & - & - & - & - & - & - & - & - \\
\hline $\mathbf{1 6}$ & - & - & - & - & - & - & - & - & - \\
\hline $\mathbf{1 7}$ & - & - & - & - & - & - & - & - & - \\
\hline $\mathbf{1 8}$ & - & - & - & - & - & - & - & - & - \\
\hline $\mathbf{1 9}$ & - & - & - & - & - & - & - & - & - \\
\hline $\mathbf{2 0}$ & - & - & - & - & - & - & - & - & - \\
\hline $\mathbf{2 1}$ & - & - & - & - & - & - & - & - & - \\
\hline
\end{tabular}

Minimum inhibitory concentration of $S$. aureus isolates against methicillin from nasal swabs of diseased cats

Total of three samples were shown their resistant at the concentration of $16 \mu \mathrm{g} / \mathrm{ml}$ in diseased cats while remaining shown no resistant at any concentration of methicillin. The positive sign indicates the bacterial resistant against methicillin and negative sign shows no growth of $S$. aureus against methicillin (Table 6).

Molecular characterization of $S$. aureus isolated from diseased dogs and cats

The result of PCR assay showed that all the five phenotypically methicillin resistant samples of dogs did not carry mec-A gene and all three phenotypically methicillin resistant samples of cats were not carry $m e c-A$ gene hence confirmed that there was no MRSA in nasal swabs of diseased dogs and cats. The electrophoresis processes showed absence of mec- $A$ gene in any samples. The PCR amplified picture shows the marker of 2000bp.

\section{Discussion}

This study was designed to detect the Methicillin resistant $S$. aureus from nasal swabs of diseased dogs and cats and to confirm that $S$. aureus carrying genetic material responsible for their resistant to methicillin or not. During this study, 37 samples were found positive with $S$. aureus from100 nasal samples in dogs and cats (Table 1). Prevalence was observed comparatively higher in diseased dogs than diseased cats for $S$. aureus at Hyderabad. Similarly, Habibullah reported that among the 93 samples, $38(40.86 \%)$ was found positive for $S$. aureus in pet dogs and cats at 
Dhaka city. This prevalence of $S$. aureus result is in line with present study.

During present study, no positive strain of Methicillin resistant $S$. aureus from nasal swabs of diseased dogs and cats but, $8 \%$ of pet samples were infected with MRSA and in addition $5(10 \%)$ samples of dog were positive with MRSA and $3(6 \%)$ cat samples were positive with the MRSA which is in disagreement with our study as we found no positive samples for MRSA.

The bacterial isolates of this study were confirmed by their typical growth pattern and colony characteristics, which include beta hemolytic activity on blood agar (Fig. 1) [12] mentioned that $S$. aureus is found hemolytic on blood agar, whereas $S$. epidermis is no hemolytic, thus it confirms that bacterial colonies observed during this study were of $S$. aureus, which has ability to produce hemolysin enzyme that lyses the red blood cells.

Morphologically $S$. aureus was found gram positive cocci often arranged in single, double or grapes like (Fig. 2). Habib et al. [13] defined morphological properties as gram positive cocci arranged in single, pairs or in chain and S.aureus were produced golden yellow and shiny colonies on nutrient agar. The bacterial isolates of this study is confirmed by the findings of above studies.

Table 6. Minimum inhibitory concentration of $S$. aureus isolates against methicillin from nasal swabs of diseased cats

\begin{tabular}{|c|c|c|c|c|c|c|c|c|c|}
\hline $\begin{array}{c}\text { Samples } \\
\text { No. }\end{array}$ & $\begin{array}{c}128 \\
\mu \mathrm{g} / \mathrm{ml}\end{array}$ & $\begin{array}{c}\mathbf{6 4} \\
\mu \mathrm{g} / \mathrm{ml}\end{array}$ & $\begin{array}{c}32 \\
\mu \mathrm{g} / \mathrm{ml}\end{array}$ & $\begin{array}{c}16 \\
\mu \mathrm{g} / \mathrm{ml}\end{array}$ & $\begin{array}{c}\mathbf{8} \\
\mu \mathrm{g} / \mathrm{ml}\end{array}$ & $\begin{array}{c}\mathbf{4} \\
\mu \mathrm{g} / \mathrm{ml}\end{array}$ & $\begin{array}{c}\mathbf{2} \\
\mu \mathrm{g} / \mathrm{ml}\end{array}$ & $\begin{array}{c}\mathbf{1} \\
\mu \mathrm{g} / \mathrm{ml}\end{array}$ & $\begin{array}{c}\mathbf{0 . 5} \\
\mu \mathrm{g} / \mathrm{ml}\end{array}$ \\
\hline 1 & - & - & + & + & + & + & + & + & + \\
\hline 2 & _ & - & + & + & + & + & + & + & + \\
\hline 3 & _ & - & + & + & + & + & + & + & + \\
\hline 4 & - & _ & _ & _ & _ & _ & _ & _ & _ \\
\hline 5 & - & - & - & - & - & - & - & - & - \\
\hline 6 & - & - & _ & - & - & _ & - & - & - \\
\hline 7 & - & - & - & - & - & - & - & - & - \\
\hline 8 & - & - & - & - & - & - & - & - & - \\
\hline 9 & _ & - & - & _ & - & - & - & - & - \\
\hline 10 & - & - & - & - & - & - & - & - & - \\
\hline 11 & - & _ & - & - & - & - & - & - & - \\
\hline 12 & _ & - & - & - & - & - & _ & - & - \\
\hline 13 & - & - & - & - & - & - & - & - & - \\
\hline 14 & - & 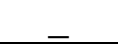 & $=$ & - & $=$ & - & - & - & \\
\hline 15 & & - & $=$ & _ & - & - & - & - & - \\
\hline 16 & - & _ & - & - & - & - & - & - & 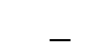 \\
\hline
\end{tabular}

The Staphylococcus aureus were confirmed by its biochemical properties, which included catalase, methyl red, urease, gelatin liquification, coagulase, oxidase positive, indole oxidase negative (Table 3). Rusenova \& Rusenov [14] reported that the biochemical properties of $S$. aureus as catalase coagulase urease positive, indole and oxidase negative. The above biochemical result is in agreement with present study.
The bacterial susceptibility to methicillin was confirmed through minimum inhibitory concentration (MIC) through using micro broth 2-fold dilution method. A concentration of $1280 \mu \mathrm{g} / \mathrm{ml}$ of methicillin was used. The $20 \mu \mathrm{g} / \mathrm{ml}$ concentration of methicillin was break point for MIC were observed in this study. Out of 37 isolates of S. aureus only 08 isolates were shown resistant to methicillin phenotypically (Table 4) 5(23.80\%) isolates were found 
moderate level of resistance to methicillin in diseased dogs. Out of $16,3(18.75 \%)$ isolates were found low level of resistant to methicillin in diseased cats (Table 5) [15]. stated that, Methicillin Resistant $S$. aureus was treated with different antibiotic, but Methicillin was the most effective antibiotic against all MRSA isolates they mentioned that some samples showed resistance to the drug even at low concentration, which indicated that bacteria are methicillin resistance.

The PCR results of the present study suggest that all methicillin resistant samples did not carry $m e c-A$ gene (Fig. 3 ). The DNA fragment of $533 \mathrm{bp}$ was amplified and confirmed as $m e c-A$ in $25 \%$ of human isolates by [16]. The findings of this study are in disagreement with our study, as we found that no $m e c-A$ gene, But in this study no band was seen at any stage of gel electrophoresis methicillin resistant isolates were only found phenotypically resistant to methicillin and the level of resistant was moderate, this phenotypical resistance may be due to the Penicillin binding protein (PBP), Beta-lactmase enzyme and methicillinase enzyme production and different strain of Staphylococcus aureus. Absence of the mec-A gene in this study can be attributed to many causes subsequently there are other mechanisms that are nonmec dependent mechanism that donate individually or in combination with different antibiotic resistance in Staphylococci isolates [17].

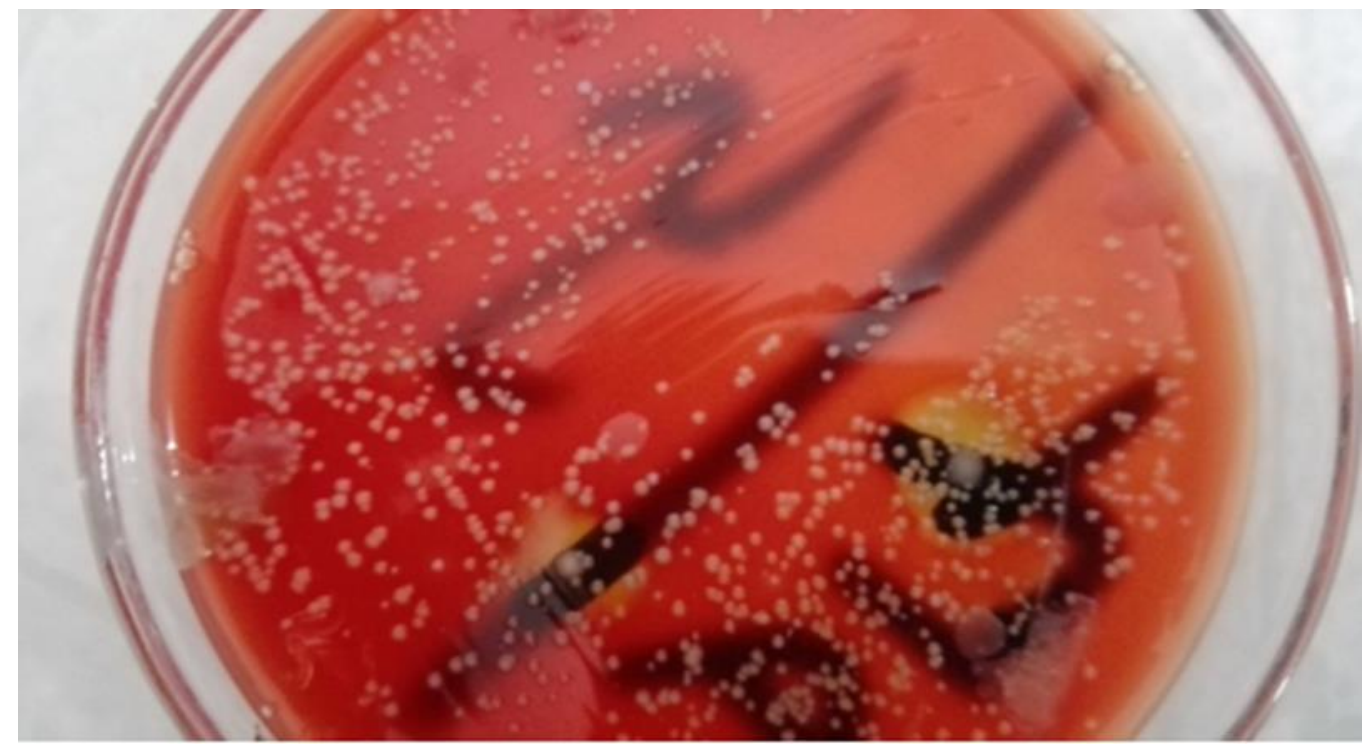

Figure 1. Colony characteristic of $S$. aureus isolates from nasal swabs of diseased dogs and cats

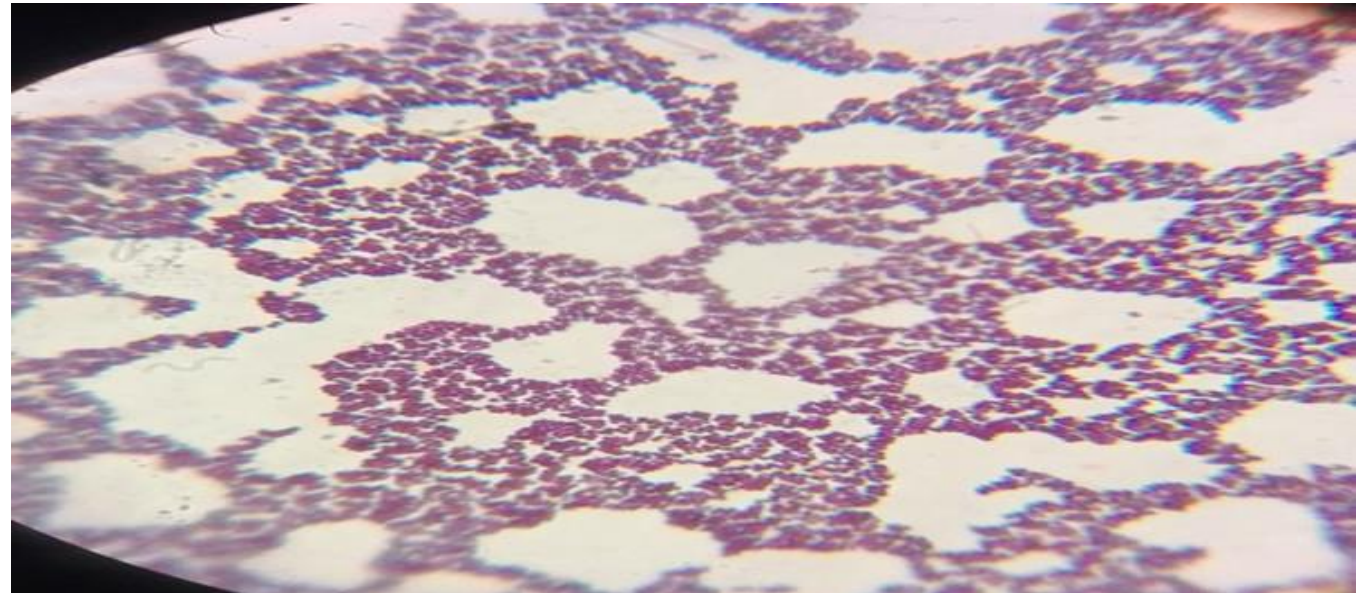

Figure 2. Add Caption biochemical characteristic of $S$. aureus isolates 


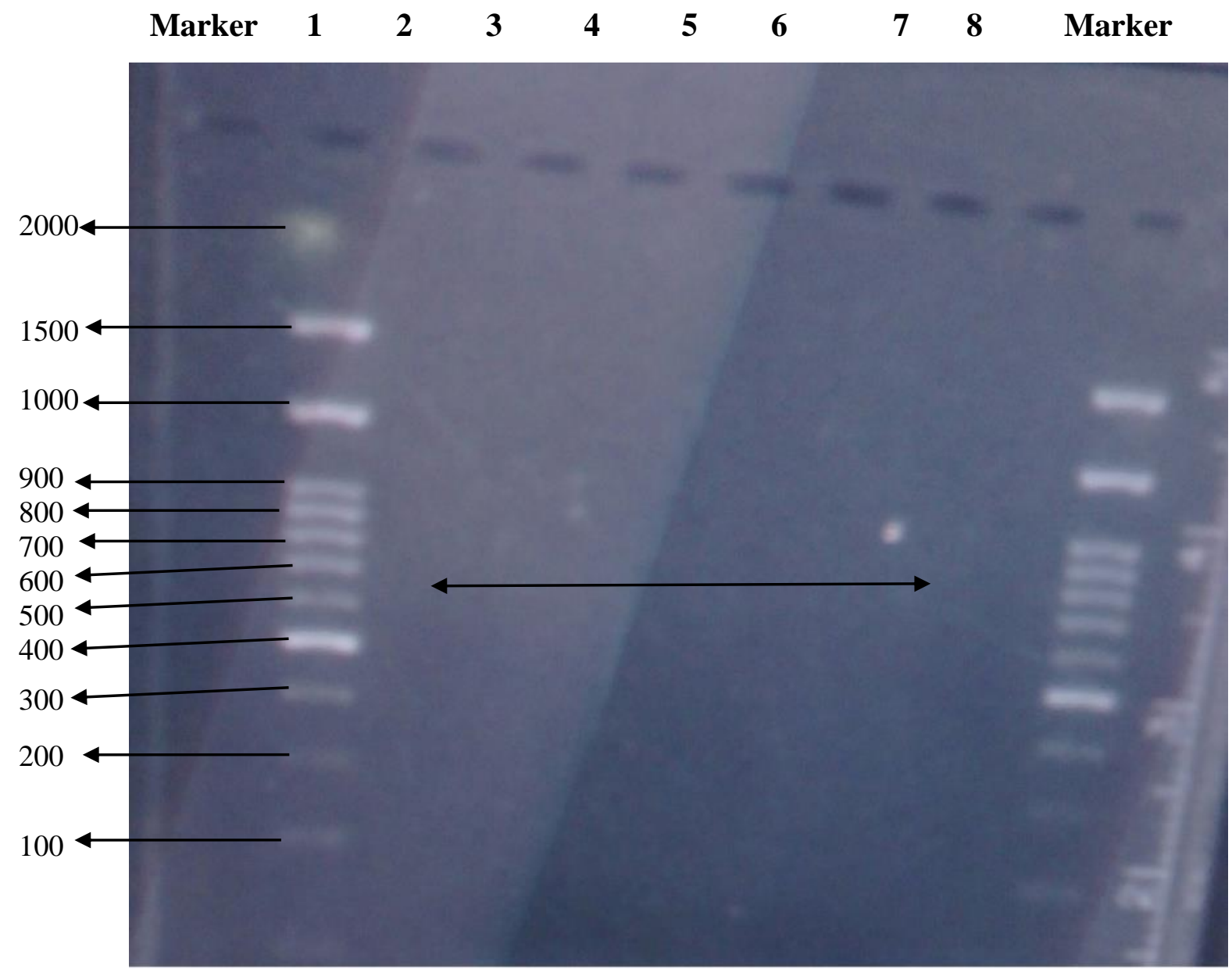

Figure 3. This gel electrophoresis result shown that no any amplified product was found at 530bp)

\section{Conclusion}

On the basis of present finding it is concluded that $S$. aureus is prevalent in nasal swabs of diseased dogs and cats. The prevalence Percentage is higher in diseased dogs as compared to diseased cats and $S$. aureus showed moderate resistant to methicillin when MIC test done but this resistant were recorded more in $\operatorname{dogs}$ as compared to cats. This resistance was due to phenotypically and moderate level of the resistance against methicillin with absence of $m e c-A$ gene shows that the examined pets are not the reservoir of mec- $A$ gene. However, more studies at the larger scale at (country level) are recommended to further confirm that the pets are reservoir for mec$A$ gene or not.

\section{Authors' contributions}

Conceived and designed the experiments: IA Ujjan, JK Zaman \& NH Kalhoro, Performed the experiments: IA Ujjan, $\mathrm{AH}$ Merani \& AL Bhutto, Analyzed the data: IA Ujjan, AN Khosa, B Sahito \& WA Vistro, Contributed reagents/ materials/ analysis tools: IA Ujjan, C Wajid \& MA Memon, Wrote the paper: IA Ujjan.

\section{References}

1. Clardy J, Fischbach MA \& Currie CR (2009). The natural history of antibiotics. Current Biol 19(11): 437441.

2. Normand EH, Gibson NR, Reid SW, Carmichael SC \& Taylor DJ (2000). Antimicrobial-resistance trends in bacterial isolates from companion 
animal community practice in the UK. J Prevent Veter Med 46: 267-278.

3. Rayner C \& Munckhof WJ (2005). Antibiotics currently used in the treatment of infectionscaused by Staphylococcus aureus. Internat Med J 35(2): 3-16.

4. Freeman-Cook L \& Freeman-Cook K (2006). Staphylococcus aureus infections. Chelsea house publishers, USA.

5. Abbott Y, Leggett Rossney A, Leonard F \& Markey B (2010). Isolation rates of MRSA in dogs, cats, and horses in Ireland. Veter Rec 166: 451-455.

6. Boothe DM (2006). Principles of antimicrobial therapy. Vet Clin Small Ani Prac 36: 1003-1047.

7. Robinson DA \& Enright MC (2004). Multilocus sequence typing and the evolution of methicillin-resistant Staphylococcus aureus. Clinic Microbiol and Infect 10: 92-97.

8. Flynn N \& Cohen SH (2008). The continuing saga of MRSA. J Infect Dis 197(9): 1217-1219.

9. Ito T, Katayama Y, Asada K, Mori N, Tsutsumimoto K, Tiensasitorn C \& Hiramatsu K (2001). Structural comparison of three types of staphylococcalcassette chromosome mecintegrated in the chromosome in methicillin- resistant Staphylococcus aureus. Antimicro Agents Chem 45:1323-1336.

10. Yamashita K, Shimizu A, Kawano J, Uchida E, Haruna A \& Igimi S (2005). Isolation and characterization of staphylococci from external auditory meats of dogs with or without otitis externa with special reference to Staphylococcus schleiferi subsp. coagulans isolates. J Veter Med Sci 67: 263-268.
11. Faires MC, Tater MKC, Pearl DL \& Weese JS (2010). Methicillinresistant and -susceptible Staphylococcus aureus infections in dogs. Emerg Infect Dis 16: 69-75.

12. Todar K (2015). Staphylococcus aureus and Staphylococcal Disease. Todars online text book of bacteriology, net/staph.html. Textbook of Bacteriology.

13. Habib F, Rind R, Durani N, Bhutto AL, Buriro RS, Tunio A, Aijaz N, Lakho SA, Bugti AG \& Shoaib M (2015). Morphological and cultural characterization of Staphylococcus aureus isolated from differ rent animal species.J Appl Environ and Biol Sci 5(2): 15-26.

14. Rusenova NV \& Rusenov AG (2017). Detection of Staphylococcus aureus Among Coagulase Positive Staphylococci from Animal Origin Based on Conventional and Molecular Methods. Macedo Veter Rev 40(1): 2936.

15. Rybak MJ \& LaPlante KL (2005). Community-associated methicillinresistant Staphylococcus aureus: A Rev Pharmaco 25: 74-85.

16. Alam M, Uddin M, Kobayashi N \& Ahmed M (2013). Detection of methicillin-resistant Staphylococcus aureus (MRSA) from animal and human origin in Bangladesh by polymerase chain reaction. Bangla $J$ Veter Med 9(2): 161-166.

17. Aklilu E, Zunita Z, Hassan L \& Chen HC (2010). Phenotypic and genotypic characterization of methicillinresistant Staphylococcus aureus (MRSA) isolated from dogs and cats at University Veterinary Hospital, University Putra Malaysia. Tropic Biomed 27(3): 483-492. 